\title{
Entre la identidad y el compromiso: un acercamiento biopolítico a He visto la noche, de Manuel Zapata Olivella*
}

DOI: https://doi.org/10.18046/recs.i30.3189

\section{Between Identity and Commitment: A Biopolitical Approach to Manuel Zapata Olivella’s He visto la noche}

\author{
Alejandro Alzate ${ }^{* *}$ \\ Universidad Católica Lumen Gentium/Universidad Icesi (Cali, Colombia)
}

\footnotetext{
* Este artículo ha sido elaborado en el marco del seminario de estudio permanente sobre la obra de Manuel Zapata Olivella que lleva a cabo la Universidad del Valle a través de su grupo de investigación en Narrativa Colombiana, al cual el autor pertenece como investigador. Artículo de investigación recibido el 19.10.2018 y aceptado el 09.09.2019.

${ }^{* *}$ Doctor en Literatura por la Universidad de Navarra (España). Docente del Departamento de Lenguaje de la Universidad Católica Lumen Gentium y la Universidad Icesi (Colombia).Correo electrónico: aalzatem@gmail.com ORCID: https:// orcid.org/oooo-0002-0832-0223
} 


\section{Cómo citar/How to cite}

Alzate, Alejandro (2020). Entre la identidad y el compromiso: un acercamiento biopolítico a He visto la noche, de Manuel Zapata Olivella. Revista CS, 30, 123-140. https://doi.org/10.18046/recs.i3o.3189 
Resumen

Abstract

En tanto expresión estética, la literatura no escapa a la influencia del poder asumido como forma de control social. En ese sentido, cabe preguntarse cómo obras escritas por autores no consagrados por las élites intelectuales y económicas asumen y explican las arremetidas de las hegemonías que excluyen, homogeneizan y tienden a consolidar discursos monológicos. Teóricamente, será la biopolítica, concepto propuesto por Michel Foucault, en 1978, la que mejor evidencie la relación entre sujeto, sociedad y poder que plantea este texto de Manuel Zapata Olivella, a partir de un viaje realizado a los Estados Unidos.

\section{PALABRAS CLAVE:}

biopolítica, negritudes, Manuel Zapata Olivella, novela colombiana, literatura del siglo XX

As aesthetic expression, literature does not escape the influence of the power considered as a form of social control. In that sense, it is worth asking how the works written by authors not consecrated by the intellectual and economic elites, assume and explain the onslaught of the hegemonies that exclude, homogenize, and tend to consolidate monological discourses. Theoretically, it will be biopolitics, a concept proposed by Michel Foucault in 1978, what best explains the relationship between subject, society, and power that this text by Manuel Zapata Olivella proposes based on a trip made to the United States.

\section{KEYWORDS:}

Biopolitics, Negritudes, Manuel Zapata Olivella, Colombian Novel, Twentieth Century Literature 



\section{Introducción}

Estudiar el conjunto de la literatura colombiana escrita por autores negros como Manuel Zapata-Olivella, Arnoldo Palacios, Helcías Martán Góngora o Candelario Obeso, entre otros, es fundamental por varias razones. La primera de ellas se articula con el reconocimiento de una tradición intelectual que ha ampliado -y discutidolos conceptos de identidad, cultura y derechos civiles en Colombia ${ }^{1}$. Una segunda razón por la cual debe estudiarse la literatura afro en nuestro país parte del hecho de poder explicar el valor literario y sociológico de novelas, cuentos, poesías y ensayos diversos. Estas expresiones son de valía en la medida que posicionan al negro -con su pensamiento místico y concreto- en el contexto cultural y político del siglo XX. En adición a lo anterior, volver sobre los clásicos de nuestra afroliteratura ${ }^{2}$ resulta importante para entender tanto el génesis como las preocupaciones de una raza que ha aportado significativamente a nuestra conformación demográfica como nación.

Planteado lo anterior, y con el fin de relacionar cultura, demografía y pugnas de poder, cabe señalar lo siguiente: si bien es sabido que los saberes de las comunidades afro han ensanchado la conformación multicultural colombiana, también lo es el hecho de que los discursos hegemónicos han pretendido, desde los inicios de la vida republicana, modelar perfiles únicos en relación con lo racial, lo dialectal y lo religioso; todo esto pasando por lo político y lo económico, desde luego. En este contexto de aportaciones y rechazos, volver sobre las huellas de lo musical, lo mitológico, lo idiosincrásico y lo literario, en el caso específico que compete a este

1. En ese sentido, la figura de Rogerio Velásquez ha sido emblemática para muchos artistas y pensadores afrocolombianos que han incursionado en la literatura, antropología, política y etnología. En el caso puntual de Velásquez, la irrupción en estos ámbitos significó conocer a fondo no solo el afroamericanismo, sino la composición de las sociedades negras en Colombia, sus luchas históricas y sus perspectivas de futuro. Teresa Martínez, Jorge Artel, Hugo Salazar Valdés y Natanael Díaz, entre otros, como propone Carlos Valderrama Rentería (2016) en Intelectualidad crítica afrocolombiana: la negredumbre en el pensamiento intelectual de Rogerio Velásquez Murillo, son tan solo algunos de los hombres y mujeres que hicieron aportes desde el folclor, la política y la educación con un fin claro: legitimar la historia racial, civil y cultural afro en Colombia durante el siglo XX.

2. Por afroliteratura entendemos no solo el conjunto de obras escritas por autores negros, sino el que reivindica al negro frente a siglos de dominación colonial. En ese sentido, es preciso entender el concepto desde una perspectiva metaliteraria que permita el diálogo con disciplinas como la sociología, la antropología y, desde luego, la economía y la política. Más allá de las categorizaciones -afroliteratura, literatura caucásica, literatura amarilla o indo-árabe- vale la pena entender obras, como esta de Zapata-Olivella, en tanto creaciones cuya visión de mundo cuestiona las prácticas que hacen indigna una experiencia vital. Cabe precisar, finalmente, que uno de los principales problemas de las taxonomías es que pueden servir más a los intereses de la crítica literaria, el canon y el mercadeo que a la propia literatura y sus tentativas de legitimación social. Para profundizar sobre este y otros asuntos relacionados con el uso del término, ver el artículo de Silvia Valero (2013). También puede consultarse el trabajo de Alain Lawo-Sukam (2011). 
artículo, es significativo no solo de cara al reconocimiento de muchos de nuestros procesos sociales, sino importante en la medida en que anima tanto la superación del aislamiento geográfico (los negros ubicados en las costas y litorales, y los blancos atrincherados en el centro del país) como la superación de los prejuicios que tildan a comunidades enteras como bárbaras. De acuerdo con Zapata-Olivella (1968: 54), "en Colombia no se le había querido dar carta de nacionalidad a estas huellas, que, lejos de aminorar sus caracteres recesivos, parece que los multiplican".

El hecho de que existan tensiones entre expresiones culturales que explican un mundo, el negro, y poderes políticos o económicos cuyo objetivo es debilitarlas, plantea para la crítica la necesidad de acercarse a obras como He visto la noche. Este título, publicado por Zapata-Olivella en 1946, puede definirse como una obra de juventud ${ }^{3}$; lo cual no niega la preocupación política y racial del autor en torno a la naturaleza y figuración social del hombre negro. Por el contrario, dicha preocupación se enuncia de manera sentida, tal como lo señala el propio escritor desde el prefacio: "si antes la ruta y el paisaje movían a inquietud mis pasos, ahora el hombre se convertía en el objeto de mi descubrimiento" (Zapata-Olivella, 1968: 7). Es justamente esta característica la que permite plantear los ejes de indagación que se desarrollarán en el presente artículo. En primer lugar, se analizará cómo es la construcción identitaria del personaje protagónico desde una perspectiva biopolítica.

En segundolugar, se revisará cómo y por qué He visto la noche puede leerse como un texto de compromiso; no en el sentido beligerante de la narrativa hispanoamericana de los años treinta ${ }^{4}$, sino desde la perspectiva integracionista de un nuevo humanismo.

3. En relación con el uso del término "obra de juventud", es importante precisar lo siguiente: si bien en la narrativa de Manuel Zapata-Olivella se percibe, en general, el interés por la reivindicación racial, cultural y política del negro, la obra que aquí se analiza es la primera que, desde la ficción, permite dar cuenta de ello. Es He visto la noche la novela que primero da a conocer su estructura de pensamiento en relación con la reivindicación histórica de su raza. Además de esto, se corresponde con su primera salida de Colombia en busca de aventuras. Tanto México como los Estados Unidos le permiten ver, in situ, el drama de los suyos y la urgencia de emprender acciones al respecto. En ese sentido, lo que descubre en estos países lo impele a tomar una posición que no abandonará nunca en su escritura: la restauración social y moral del subalterno negro que se debate entre el "ninguneamiento", la combatividad y la esperanza.

4. En relación con el compromiso que se advierte en He visto la noche, cabe señalar lo siguiente: este no se agota en la crítica única e incendiaria del capitalismo como sistema económico imperante, sino que entiende al sujeto como el principal capital de las sociedades modernas. En ese sentido, el interés no pasa tanto por la denuncia de una institucionalidad viciada y avara, sino por el deseo ecuménico de reconciliar a los hombres. Es por esto que la novela de Zapata-Olivella se separa de otras como Huasipungo (1934) o El mundo es ancho y ajeno (1941). 


\section{¿Identidades combativas o combates por la identidad?}

El hecho de que la biopolítica se defina como "aquella vertiente social ligada con las técnicas disciplinarias del poder y el control demográfico" (Foucault, 1979:34) explica, en gran medida, por qué las interacciones -culturales y económicas- de sujetos marginales como el narrador de He visto la noche son siempre vigiladas por parte de los sectores dominantes. Esta misma caracterización de la biopolítica explica las razones por las cuales las aludidas interacciones se dan, si acaso, bajo un estricto control estatal que delimita sus espacios de realización y alcances. Son estos procesos de dominación, de control de cuerpos, los que agudizan el interés de Zapata-Olivella por dar cuenta de la conflictiva relación entre el inmigrante desposeído-que nada aporta al sistema por su ilegalidad, en muchos casos-y el biopoder, que sanciona tanto su diferencia étnica como su no inserción dentro de las políticas de empoderamiento y expansionismo económico.

En el entendido de que la biopolítica observa, legaliza y controla el desarrollo social de los sujetos, resulta difícil que se construya una identificación entre el narrador y el contexto que propone la ficción. Este último, como lo evidencia la obra, tanto en México como en los Estados Unidos, opera bajo una rígida normatividad que mantiene un solo orden, el blanco hegemónicos, que no está dispuesto a fisurarse en aras del intercambio cultural y, mucho menos, racial $^{6}$. El color de la piel, la procedencia, el idioma y la condición económica marcan distancias insalvables entre aquellos que están dentro del sistema, y por lo tanto tienen el poder, y quienes no lo están, y por lo tanto son asumidos como parias, tal como se aprecia a continuación: "el personal directivo comenzó a mal mirarme por mi convivencia con los braceros: dormía igual que ellos, sobre el duro tablado de los vagones, en medio de sus cuerpos calientes y sudorosos que se bamboleaban como racimos en el balanceo de la locomotora" (Zapata-Olivella, 1968: 20).

En el descrito escenario, identificarse con los acontecimientos que van sucediéndose uno tras otro es imposible. El hacinamiento, máxima expresión de unión entre seres que no se conocen, pero que tienen en común la lucha por la supervivencia,

5. La discusión en torno a la hegemonía como concepto es amplia. No obstante, y para efectos del presente artículo, se seguirá lo planteado por Lawrence Grossberg (2004: 52), donde lo hegemónico se asume "menos como la construcción de un sentido de unidad [y más] como la aceptación de una estructura de mando y control".

6. En adición a esto, los contextos que se proponen están mediados por la precariedad, el peligro y la violencia que ejercen, sin remordimiento, capataces y ciudadanos indolentes. Tanto México como los Estados Unidos golpean a inmigrantes que ponen la otra mejilla para no morir de hambre en una geografía extraña y abstracta como un poema cubista. 
agudiza el control que ejercen aquellos a quienes el sistema ha legalizado para vigilar. A raíz de esto, el único vínculo que puede establecerse entre los braceros es el de una íntima y silenciosa comunión simbólica. Esta justifica, o hace más llevaderos, tanto el padecimiento como el dolor, cuando el objetivo es obtener una vida mejor. Al mismo tiempo que el contexto golpea, por su dureza, la lucha común agudiza los procesos de identificación entre los marginados.

Ahora, aun cuando las condiciones sociales se presenten más amables: "Jorge fue el amigo que me ayudó a entender el sentido de la vida norteamericana (...) su generosidad se abrió para mí como la despejada mente de los científicos ante un experimento" (Zapata-Olivella, 1968:43), la identificación con seres y entornos tiene lugar entre el combate y la imposibilidad. Estas instancias, productos residuales de la ideología capitalista, tienen un doble rostro. Por un lado, no garantizan el acceso del sujeto marginal al centro de la cultura hegemónica y, por otro, lo obligan a rescatar sus raíces, sobre todo las culturales, como estrategia de lucha: "dos dólares valía la entrada más baja al concierto de Marian Anderson ${ }^{7}$ y pese a que no había encontrado dinero para recobrar mis ropas, me entusiasmé a tal grado que reinicié la búsqueda de aquellos dólares a fin de apreciar, ante una multitud blanca y negra, su canto que para mí tenía el aliento de un himno de rebelión" (Zapata-Olivella, 1968:144). Quizá, uno de los encuentros que más redime el alma abatida del narrador-protagonista es el que acontece con el poeta e intelectual negro Langston Hughes ${ }^{8}$.

Toqué sus puertas esperanzado en que me ayudara a vender algún artículo en los periódicos negros, pese a que no había visto ninguno editado en Nueva York. Detrás de esta ayuda que pensaba solicitarle, se escondía la profunda admiración que como hombre y poeta me habían despertado los relatos de su vida y los pocos poemas que le conocía. En el poeta encontré mucho más de lo que abrigara mi alma abatida: un amigo. (Zapata-Olivella, 1968: 126)

La riqueza de este suceso, que aviva la identificación del marginado con quien funge como autoridad cultural y literaria reconocida y, por lo tanto, es capaz de

7. Esta cantante, nacida en Filadelfia en 1897, encarnó el espíritu de lucha de las comunidades negras de los Estados Unidos. Su presencia en el panorama artístico, entre 1930 y 1960, significó la apertura de la escena musical internacional para los cantantes negros de su país. Europa le ofreció sentidos reconocimientos, al tiempo que lo propio sucedió en EE. UU. En esta nación, Anderson cantó para los presidentes Roosevelt, Kennedy y Eisenhower.

8. Poeta, cuentista, novelista y periodista norteamericano nacido en Misuri, en 1902. Se reconocen sus importantes esfuerzos y gestiones para la consolidación de lo que se denominó "Renacimiento del Harlem”. Este movimiento buscó fusionar la poesía y la música; tanto así que Hughes se destacó como el principal exponente de la Jazz Poetry. 
generar confianza en las potencialidades artísticas del novato narrador, es apenas equiparable con la que resultó del encuentro con el escritor peruano Ciro Alegría, de quien dice lo siguiente:

Bastó con que yo le expresara mi angustiosa situación de ayuno y dispersión espiritual, para que abriera su comprensión a mis necesidades de peregrino. No fue difícil mostrarle mis juveniles experiencias a sus ojos que tanto habían visto. Alegría no asumió su papel de catedrático, sino que compartió mis inquietudes y necesidades apremiantes a son de camaradería. A los pocos minutos de conocernos me invitó a almorzar para dar aliento a mis débiles palabras y al despedirnos me desconcertó al darme una prueba de confianza, prestándome su máquina de escribir portátil a fin de que yo pudiera sacar en limpio algunos artículos que quería mostrarle. (Zapata-Olivella, 1968: 127)

Si bien estos encuentros transcurren en medio de una notable cordialidad, es preciso mencionar que ni Hughes ni Alegría ni el mismo Jorge pueden garantizar que el resto de los ciudadanos acompañen al inmigrante en su reconocimiento, político y cultural, de la sociedad norteamericana. Por fuera de los lazos de respeto y camaradería que con ellos se dan, el resto de la ciudadanía que deambula por las páginas del libro está presta para la sanción y el "ninguneamiento" social, y es ahí, justamente, donde el combate por la supervivencia se pone de manifiesto como vía de hecho para tener un lugar en los Estados Unidos.

Ahora bien, nada garantiza, tampoco, que tras el combate se triunfe en los restaurantes, buses, hoteles y todos aquellos espacios de la vida cotidiana donde el negro es severamente discriminado. De hecho, y de acuerdo con la obra, es más factible que la imposibilidad se imponga y eche al traste los intentos desesperados por ser parte de una sociedad cerrada y endogámica. Nótese, por ejemplo, que es la imposibilidad la que priva al narrador de asistir al concierto de Marian Anderson referido líneas arriba: "a la hora de iniciarse el concierto, abatido por el cansancio y por la honda amargura de no haber conseguido con qué comprar el boleto de entrada, me acerqué al teatro ya sin esperanza de escucharla" (Zapata-Olivella, 1968: 144).

En ese contexto de desamparo, el inmigrante es vencido, una vez más, por la realidad que le niega participar del acontecer cultural y reivindicativo de los Estados Unidos; nación que, para 1946, se recuperaba de las heridas económicas y espirituales ocasionadas por la segunda Guerra Mundial. A la luz de estas dificultades o combates, cabe analizar lo siguiente: si la identidad no se construye fácilmente en la obra, tampoco se ha podido construir como concepto, y satisfactoriamente, en los ámbitos intelectuales y académicos. Desde esa perspectiva, y antes de analizar la construcción identitaria del protagonista de He visto la noche, es preciso dar cuenta de una situación problemática en torno a la definición y ubicación de esta noción en Occidente. 


\section{Identidad: interrogantes y avances. Tránsitos cognitivos en torno al tema}

Como categoría epistémica, la identidad sigue siendo, hoy en día, punto de encuentro y desencuentro semántico y teórico. Para algunos filósofos clásicos, como Parménides o Platón, aquellos rasgos que le daban al hombre sus características, cualidades o atributos, es decir, su identidad o definición, eran invariables y estáticos. A su vez, para filósofos contemporáneos como Nietzsche o Heidegger, la identidad es una categoría imprecisa. Para estos últimos, lo trascendental, lo atemporal y lo universal no podían erigirse, per se, como los atributos que definieran la naturaleza del ser.

Ante estos disensos, se introduce el carácter aporético de la identidad; esto significa, de acuerdo con Zaira Navarrete Cazales (2008:5), que "la identidad (...) tiene la condición de necesariedad y a la vez de imposibilidad, es decir, es un concepto que es necesario para hablar de algo que caracteriza temporal o históricamente a un sujeto o a un campo disciplinario pero, a la vez, es imposible de representación precisa y definitiva". En ese sentido, y siguiendo el pensamiento de Navarrete Cazales, la identidad pasa a ser una construcción discursiva mediada y condicionada por contextos, situaciones y realidades siempre cambiantes y movedizas.

La dificultad para explicar el término de manera concisa ha hecho que autores como Stuart Hall o Jean-Bertrand Pontalis, entre otros, hayan coincidido en que resulta mejor aludir al término "identificación", para poder acercarse a una interpretación de la identidad como categoría epistémica. Por identificación se entenderá, entonces, y de acuerdo con Hall (2000: 230), "un proceso de articulación, una sutura, una sobre determinación y no una subsunción. [Este proceso] se fundamenta en la fantasía, la proyección y la idealización". De esta definición destacamos la alusión al proceso de articulación, mas rechazamos la noción de idealización, pues deslocaliza las luchas concretas, al tiempo que niega las posibilidades de concreción histórica a los procesos de identificación. De aceptar esta tesis, el personaje de He visto la noche y el propio Zapata-Olivella se quedarían en un plano netamente proyectivo, alejado de cualquier tipo de concreción, en términos de inclusión y reivindicación. Mejor nos parece, en términos culturalistas, lo planteado por Homi K. Bhabha (1996: 56), al "tratar la identidad desde la diferencia, como expresión de diversidad, esto es, el reconocimiento de las minorías, de los excluidos, que tienen posibilidad de visibilidad social solo a partir de los otros".

Esto último es relevante pues, justamente, los otros, los negros norteamericanos, son quienes permiten al protagonista buscar sus raíces. El viaje posibilita al narrador el encuentro de sí mismo entre los demás que, como sugiere Bhabha, también son excluidos y, por lo tanto, desconocidos en su diversidad y diferencia. Durante el 
periplo por los Estados Unidos hay una sanción permanente a través de la cual los integrantes de la cultura hegemónica descalifican y reducen al otro. El diferente es problematizado en tanto agente de contaminación demográfica. Desde ese presupuesto hermenéutico, la biopolítica se manifiesta como un instrumento de control que soporta las tentativas de superioridad racial o predominancia de una etnia o grupo. La narración pone en evidencia cómo en una de las naciones más desarrolladas del mundo, como dice el narrador, se dan algunos de los procesos de pauperización más aberrantes del mundo, como consta a continuación:

$\mathrm{Al}$ acercarme a la barra del restaurante de la Grayhound, tuve la fortuna de que me despachara la muchacha negra, quien ya se disponía a abandonar su turno. iDeme un pudín y un vaso de leche! La muchacha me respondió un poco turbada: no le puedo servir, señor. Si usted quiere, le despacho lo que me pide pero debe comérselo fuera de aquí. Será mejor que se levante de la silla pues hay muchos clientes blancos y sin duda lo obligarán a que la abandone. En las corteses explicaciones de la muchacha comprendí que había adivinado mi acento de extranjero. De buen agrado hubiera platicado con ella acerca de lo que experimentaba con su anuncio, mas tuve que dejar la silla. Ya estaba allí un gringo alto, de tez rubicunda y sombrero tejano. La muchacha, adivinando su intención, me hizo poner de pie antes de que aquel se dirigiera a mí. Con el pudín y un vaso de papel rebosante de leche en las manos, torné al salón de espera. (Zapata-Olivella, 1968: 151)

Lo anterior pone de manifiesto no solo la degradación del excluido, sino, también, la imposibilidad que se reitera para negarle el ingreso al centro de la infranqueable civilización norteamericana. Nótese, metafóricamente, cómo el comer reúne y excluye al mismo tiempo. Los comensales que gozan de acceso al centro de la sociedad, por su raza, se empoderan y construyen espacios de resistencia desde donde devoran a los otros. Así, y de acuerdo con Foucault (1987: 22), "el sentido histórico no rechaza el sistema de su propia injusticia. Mira desde un ángulo determinado con el propósito deliberado de apreciar, de decir sí o no". Por otra parte, el rechazado no puede comer, es decir, no es atendido en el interior del local que se erige como centro de interacciones sociales, razón por la cual es devorado, simbólicamente, tanto por el contexto como por los demás comensales que le niegan el acceso a la mesa.

Al quedar por fuera de los principales circuitos donde se afianza la identificación social, la identidad no se puede construir. Esta tentativa es truncada y totalmente aporética; o lo que es lo mismo, necesaria, pero imposible una vez más. La identificación, por el contrario, se va tejiendo entre los desposeídos a través del confinamiento a la periferia, a los extramuros o al barrio como punto de encuentro. 
En el barrio negro encontré el calor de mis hermanos de piel (...) lo que más me interesaba era el ambiente popular de las barriadas negras. Me daba a la tarea de recorrer horas y horas South Park-Avenue, la más concurrida arteria de aquellos contornos. Los niños patinaban incansablemente de un lado para el otro; la pelota de béisbol saltaba a través de los cristales de los muchos salones de belleza donde las negritudes acudían a enderezar sus torcidos cabellos con sugestivos peinados, de indudable inspiración africana. La alegría se enraizaba en los cines, en las esquinas y en las abundantes ventas de discos grabados por los más populares cantantes negros. Bajo la lluvia de luces y colores, por entre el retumbar de los pesados y viejos tranvías que hacían el servicio por aquella barriada muy cerca del calor y de los gestos de tantos rostros de ébano, las horas me pasaban inadvertidas como niño que admirara una feria de juguetes. (Zapata-Olivella, 1968: 81)

No obstante la alegría del fragmento, esta tiene siempre un carácter efímero; situación que pone de manifiesto el enraizamiento que da a la tragedia la impronta de marca o lastre. A lo largo de toda la obra, se superponen los correlatos de la redención y la condena, del día y la noche. Si bien la experiencia social y espacial del barrio da cuenta de desarrollos y afianzamientos desde lo comunitario, también tiene aparejada una contracara: aquella que niega la completitud de una experiencia social capaz de redimir a una comunidad entera.

No todo, sin embargo, alegraba la observación. Entreverados con la alegría, también el dolor, la miseria y la morbosidad, revelaban sus caretas amargas. Con frecuencia algún niño me solicitaba algo que comer o bien, con los pantalones raídos y con sombreros viejos, demasiado grandes para sus cabecitas, arrastraban algún carro con frutas o conducían una carreta de tiro al lado de sus padres. En el cruce de las calles principales con la South Park Avenue, los "girl-boys", muchachos afeminados, paseaban sin descaro su homosexualidad con los labios pintarrajeados, el cabello ondulado y las miradas ardorosas para los hombres. Su espectáculo, muy repetido por las noches en las esquinas, me producía un sentimiento desgarrador. (Zapata-Olivella, 1968: 82)

Si bien la identificación que se logra a través de las interacciones barriales da sentido a la construcción de ciudadanía, y fortalece, además, relaciones de favor, apoyo o intercambio, cabe mencionar que la aparición de sujetos como los girl-boys fractura la identificación como eslabón para aproximarse a la identidad. De los niños desamparados a los chicos afeminados hay un abismo que complejiza, aún más, el proceso de construcción de comunidad. La resistencia hecha a partir de procesos de diferenciación sexual deja de lado la lucha racial para cuestionar la rigidez de género del heteropatriarcado. Todo esto, como puede suponerse, da pie a nuevas sanciones y exclusiones. A raíz de esto, el negro es discriminado no solo por los 
blancos, sino por aquellos negros que rechazan la alteración o modificación de la sexualidad convencional. Observado desde la biopolítica, esto es significativo porque da cuenta del rango de control que ejerce el Estado a través de la alienación de sus ciudadanos. Una vez uniformados en torno a algo, estos actúan como aparatos de poder. La raza, la identificación sexual y el género devienen, entonces, como hechos o manifestaciones proclives a la sanción cuando desbordan los límites trazados por la historia, la cultura y la ideología dominante.

En ese orden de ideas, la discriminación sexual implica procesos de aislamiento en un espacio ya aislado, es decir, en el caso de los girl-boys, estos ocuparán la periferia de la periferia, pues el centro de ese espacio ya sancionado por la política y la cultura lo ocupan todos aquellos que desde cierta, o ciertas uniformidades, buscan defender aquello que consideran único y legítimo. Si bien la actitud del narrador para con los girl-boys es amable, aunque crítica y revestida con un alto grado de tensión, queda claro que las sexualidades divergentes constituyen un problema para la biopolítica que se erige como base para la construcción idealizada del Estado. Tras el encuentro con uno de los afeminados jóvenes negros dice el narrador:

No pude continuar fingiendo más, pero contuve mis reacciones para no explotar en un ataque de machismo. Le hablé en voz ronca y contundente: soy médico y le he permitido su charla para ver qué grado ha alcanzado su enfermedad. El hombre proyectó en su rostro una expresión de asombro, pero sin avergonzarse, argumentó: entonces, perdóneme... Buscaré a otro, necesito hacerlo. Ya se retiraba, cuando alargué la mano y lo contuve por el brazo. ¿Quiere usted tomarse un refresco conmigo? Se sorprendió más aún y estuvo a punto de negarse a recibir mi invitación, pero yo le expliqué: me interesa su caso médico-social. (Zapata-Olivella, 1968: 83)

Si bien el fragmento es contundente al mostrar la imposibilidad de una identificación mínima, si quiera, no niega un hecho importante: de acuerdo con el espíritu conciliador del texto, el hecho de tender puentes de diálogo y no sancionar ni la expresión ni la expresividad de quienes portan una sexualidad diferente, da cuenta de un ejercicio de comprensión de la realidad, de la otredad y de lo heterogéneo que alterna tanto con la homogeneidad del discurso oficial como con la cultura dominante. Si se observa en detalle el fragmento, se puede inferir que los verbos permitir y recibir habilitan un espacio dialógico en el que las diferencias ideológicas se encuentran para vencer los procesos de exclusión; con lo cual no solo se reconoce al otro, sino que se le comprenden su historia y filiaciones, así como los procesos de su construcción interior.

A manera de síntesis, es preciso hacer hincapié en lo siguiente: He visto la noche propone procesos de identificación a un tiempo concretos y truncados. En la me- 
dida en que los habitantes de la periferia se reconocen a través de la precariedad y los embates de una cotidianidad excluyente, hay un proceso concreto de diálogo y reconocimiento. Ahora bien, en el entendido de que la sexualidad separe porque la diferencia no está normalizada ni incorporada completamente a la experiencia social, se trunca la posibilidad de identificación o comunión; mas no se frustra la de diálogo.

\section{Manuel Zapata-Olivella y el papel del intelectual comprometido}

El debate en torno al compromiso y la función social de la literatura es amplio y contradictorio. Las posturas que ubican al escritor como un intérprete de la sociedad y sus procesos políticos, económicos y culturales, o como un esteta sin más responsabilidad que la de entretener a las masas, coexisten en el horizonte crítico y académico desde principios del siglo XX. En el caso hispanoamericano, por ejemplo, la narrativa de los años treinta y cuarenta denunció, de manera contundente, los atropellos de las transnacionales en busca de lucro y expansionismo económico e ideológico. Obras como Regina Landa (1939) y Avanzada (1940), ambas de Mariano Azuela, entre otras, se sumaron a un importante conjunto de novelas como Huasipungo (1934), de Jorge Icaza; El mundo es ancho y ajeno (1941), de Ciro Alegría; y El tungsteno (1931), de César Vallejo, para hacer frente tanto a los desmanes y permisividades del Estado como para evidenciar realidades sociales precarias en las cuales el campesino, el indio, el negro y el sujeto emergente no conseguían una experiencia vital que los redimiera de la pobreza y la exclusión.

No obstante la importancia de esta literatura, dada su crítica a contextos, realidades y situaciones, diferentes generaciones de estudiosos la han tildado como precaria, panfletaria y carente de la estética propia del discurso literario. En ese sentido, autores como Harold Bloom han considerado que lo que importa de la literatura es su valor estético y no ideológico. En El canon occidental, una de sus obras principales, el norteamericano señala que la literatura debe contribuir principalmente "al crecimiento de nuestro yo interior" (Bloom, 1994: 30); razón por la cual el lector debe ser asumido no como "un ser social sino como un yo profundo" (Bloom, 1994: 10).

Posturas como estas niegan la función política del texto literario y lo reducen a un mero ejercicio de composición técnica. Asimismo, desconocen que el artista siempre tiene un compromiso: en primer lugar, con el arte mismo, como lo sugería Borges, $\mathrm{y}$, en segundo, con un conglomerado poblacional que lo insta a pensar y explicar lo circundante y sus valores. De acuerdo con esto último, Todorov (1991: 91) sugiere que la literatura es importante porque nos dice "cuál es la verdad de este mundo y qué es 
justo e injusto". Si esto parece demasiado al rayar con la idealización, las palabras de Sartre establecen un sensato punto medio. Para él, "el escritor (...) está en el asunto haga lo que haga, marcado, comprometido hasta su retiro más recóndito. (...) tiene una situación en su época; cada palabra suya repercute. Y cada silencio también" (Sartre, 1950:16). Resulta muy lúcido el mismo Sartre al decir, además, que el verdadero compromiso del escritor, más allá de revelar la realidad, pasa por transformarla.

A partir de este presupuesto conceptual, pueden decirse varias cosas en relación con He visto la noche. En primer lugar, Zapata-Olivella revela la realidad del negro con el firme objetivo de evidenciar el conjunto de arbitrariedades que en torno a él se levantan, como barreras infranqueables, promovidas por largos siglos de dominación colonial. Segundo, revelar la realidad constituye el primer paso para poner de manifiesto la existencia de dos problemas puntuales: la discriminación, y la exclusión social y política. En tercer lugar, el hecho de denunciar a través de la narrativa posibilita la visibilidad del escritor que, en no pocos casos, y como consta a continuación, ha sido leído con falta de perspectiva histórica y conocimiento de sus luchas e intereses: el colombiano Manuel Zapata-Olivella, dice Francisco Morales Padrón (1983: 69), "es un radical, un exagerado, un denunciador y un panfletario".

La sobreadjetivación pone de manifiesto la miopía existente en torno a las formas de hacer una crítica literaria que reivindique los textos ante la historia y las comunidades. Lo dicho por Morales Padrón descalifica a un autor estudioso de los procesos históricos de las negritudes y de su diáspora por el mundo. La crítica, así planteada, corre el riesgo de volverse ahistórica y lejana de su sentido originario; esto es, tender puentes interpretativos al lector para que comprenda mejor una obra en sus componentes estéticos, políticos, sociales y culturales. Leer a Zapata-Olivella de la manera en que lo hace el estudioso aquí referido es negar lo que, a juicio de Sartre, permite el estadio mayor del quehacer literario: la anhelada transformación. Aunada al ya referido proceso de revelar la realidad del negro, esta se evidencia con claridad desde el prefacio:

He aquí en este libro el testimonio de las inquietudes que aquejaban al negro, sus primeras luchas por forjarse una conciencia étnica, la aspiración aún confusa de ser considerado como un ciudadano sin tener que desteñirse la piel (...). Los tumultos que conmueven diariamente a la nación norteamericana, en el profundo sur y aun en el norte, donde el consentimiento de las barriadas negras no basta como ejemplo de "libertad", hacen de las páginas de He visto la noche un documento muy aleccionador de la época embrionaria de esa lucha. Es un relato objetivo de cómo se maduran las mentes de los líderes negros y cómo, tal vez sin proponérselo, buscaban la fórmula ideal para integrarse realmente a la cultura universal, reclamando el sitio que en ella deben tener los pueblos con su total autenticidad. Ejemplo combativo valedero no solo para 
las minorías raciales sino para la gran población mestiza de Hispanoamérica, ya en la encrucijada de asumir la defensa integral de su mestizaje o perderse en la frustración de un constante desconocerse a sí misma. (Zapata-Olivella, 1968: 5-6)

Con estas palabras, el escritor asume como suya la tarea de contribuir a la transformación de la realidad de un importante sector demográfico hispanoamericano; esto a través del llamado de conciencia que estimula el despertar de las mentes, como bien dice el fragmento. Así, del "ninguneamiento" al reconocimiento, del blanqueamiento a la reafirmación de valores sociales y culturales, y del ocultamiento a la presencia social con disfrute de autenticidad, hay un claro propósito en el cual el ser humano -el negro en este caso- se convierte en actor de una literatura que, como plantea David Viñas Piquer (1955: 79):

\section{Deja de lado las cosas prescindiendo de ellas u otorgándoles su verdadero valor porque no son sino ayudas, ingredientes, excusas para pasar a hacer una literatura de hombres, pero de hombres que no estén sometidos a fuerzas inefables o a determinismos orgá- nicos o psíquicos, o geográficos o clasísticos sino de hombres que se vayan haciendo a sí mismos y a su contorno, utilizándose a sí mismos y a todo lo que los rodea.}

Es la "descosificación" de la escritura la que permite señalar que He visto la noche propone una literatura para hombres que crea compromiso y sinergias. Los encuentros del narrador con Langston Hughes y con los obreros oprimidos de Winston Salem, por ejemplo, dan cuenta de la reunión de esfuerzos, intereses y vocaciones cuyo objetivo es exigir derechos y justicia. No en vano, en el mencionado pueblo, "cuya única industria consistía en la elaboración de tabacos y cigarrillos" (Zapata-Olivella, 1968:162), el narrador participa activamente de una marcha cuya arenga denunciaba los abusos cometidos contra los trabajadores por parte de los empresarios del tabaco: "en los carteles que portaban los huelguistas se leían frases como estas: iestos patrones son injustos!, iaquí pagan salarios de hambre!, iqueremos ganar para nuestros hijos!" (Zapata-Olivella, 1968: 164).

Desconocer que intervenciones como la presente son muestra de compromiso con la condición civil del hombre negro es ignorar el sentido último de esta obra de iniciación de Zapata-Olivella. Asimismo, negar el valor que tiene la unión de los huelguistas, blancos y negros, es minimizar la lucha del escritor a favor de la construcción de una sociedad justa e incluyente. Bien sabía el lorincano ${ }^{9}$ que "el emboscado no aguarda a que el enemigo admita argumentos $\mathrm{y}$, mucho menos, a

9. Este adjetivo gentilicio hace referencia al nacido en Santa Cruz de Lorica, municipio de Córdoba, Colombia. 
que se comporte con caballerosidad" (Jünger, 2002: 126). En ese sentido, la sinergia es la única forma que queda para consolidar un frente común de lucha. Cuando la opresión aqueja por igual a los trabajadores sin distinción de raza, se consolida un solo cuerpo proletario que, a la larga, traduce el pensamiento combativo del autor.

En su condición de antropólogo, Manuel Zapata-Olivella entendía bien que las sociedades modernas y avanzadas culturalmente, es decir, aquellas iluminadas por el humanismo, solo podrían superar los discursos monológicos cuando se dieran las condiciones para una rebelión solidaria; cohesionada espiritual e ideológicamente. Este principio, en la misma vía de lo propuesto por Rafael Aguilera Portales (2010: 41), al señalar que "el emboscado no puede permitirse el indiferentismo", se evidencia a lo largo de la narración cuando quien cuenta y vive los hechos se enternece, identifica, sufre o aflige por la vida que llevan seres que, incluso siendo desconocidos para él, despiertan, a raíz de sus luchas por la supervivencia, los más hondos vínculos de comunión y simpatía.

A manera de conclusión, He visto la noche es un clamor que se eleva contra la subalternidad y la invisibilización de una cultura rica, como la negra, capaz de dinamizar las anquilosadas y acomodaticias interpretaciones de la cultura universal. Por otra parte, el rescate del ser humano, asumido como fuerza transformadora, es lo que constituye el más valioso aporte de este texto. Asimismo, la reivindicación y la resistencia se presentan como una díada vital para afrontar los embates de la cultura dominante.

Desde esa perspectiva, el concepto de literatura, dice Zapata-Olivella (1997: 119), en La rebelión de los genes, "no puede ser generado, guiado e impuesto desde las metrópolis colonizadoras"; esto en la medida en que sus intereses van tras la dominación que no reconoce la súplica; práctica esta última que debe ser proscrita de las sociedades modernas. Si bien la obra pone de manifiesto que la lucha por la inclusión social no es fácil, la historia, a su vez, evidencia que tampoco es imposible. Así lo demostraron Martin Luther King y otros líderes afro, apenas unos años después de la presentación de este libro, en el mismo suelo norteamericano que sirvió de escenario a esta historia. 


\section{Referencias}

Aguilera-Portales, Rafael (2010). Biopolítica, poder y sujeto en Michel Foucault. Revista de Filosofia, Derecho y Política, 11, 27-42.

Bhabha, Homi K. (1996). Culture's In-Between. En Questions of Cultural Identity (pp. 53-60), editado por Stuart Hall; Paul du Gay. North Yorkshire: Sage Publications.

Bloom, Harold (1994). El canon occidental. La escuela y los libros de todas las épocas. Barcelona: Anagrama.

Foucault, Michel (1979). Microfisica del poder. Madrid: La Piqueta.

Foucault, Michel (1987). Historia de la sexualidad 1. La voluntad de saber. México: Siglo XXI.

Grossberg, Lawrence (2004). Entre consenso y hegemonía: notas sobre la forma hegemónica de la politica moderna. Carolina del Norte: University of North Carolina.

Hall, Stuart (2000). ¿Quién necesita la identidad? En En los márgenes de la educación. México a finales de milenio (pp. 27), coordinado por Rosa Nidia Buenfil. México: PyV/SADE.

Jünger, Ernst (2002). La emboscadura. Barcelona: Tusquets.

Lawo-Sukan, Alain (2011). (A)cercamiento al concepto de la negritud en la literatura afro-colombiana. Texas: Texas University.

Morales-Padrón, Francisco (1983). América en sus novelas. Madrid: Cultura Hispánica del Instituto de Cooperación Iberoamericana.

Navarrete-Cazales, Zaira (2008). Construcción de una identidad profesional: los pedagogos de la Universidad Nacional Autónoma de México y de la Universidad Veracruzana. Revista Mexicana de Investigación Educativa, XIII(36), 143-171.

Sartre, Jean-Paul (1950). ¿Qué es la literatura? Buenos Aires: Losada.

Todorov, Tzvetan (1991). Crítica de la crítica. Barcelona: Paidós.

Valderrama, Carlos A. (2016). Intelectualidad crítica afrocolombiana: la negredumbre en el pensamiento intelectual de Rogerio Velásquez Murillo. Bogotá: Universidad Central.

Valero, Silvia (2013). ¿De qué hablamos cuando hablamos de "literatura afrocolombiana"? O los riesgos de las categorizaciones. Medellín: Universidad de Antioquia.

Viñas-Piquer, David (1955). Benito Lynch: la realización del Facundo. Contorno, 5-6, 16-21.

Zapata-Olivella, Manuel (1968). He visto la noche. Medellín: Bedout.

Zapata-Olivella, Manuel (1997). La rebelión de los genes. El mestizaje americano en la sociedad futura. Bogotá: Altamira. 